\title{
EFECTO DE LA REHABILITACIÓN PULMONAR EN LOS NIVELES DE ANSIEDAD Y DEPRESIÓN EN PACIENTES CON ENFERMEDAD RESPIRATORIA CRÓNICA
}

Diana Jimena Cano Rosales ${ }^{1}$, Leslie Katherine Vargas-Ramírez ${ }^{1}$, Fabio Bolivar Grimaldos ${ }^{2}$, Lizeth Rodriguez Corredor ${ }^{1}$, Katherine Rincón Romero ${ }^{1}$, Katherine Rojas ${ }^{1}$, Mariana Villamizar ${ }^{2}$, Nicolás Farelo ${ }^{2}$

1. Instituto Neumológico del Oriente2. Universidad Industrial de Santander. Bucaramanga, Colombia.

OBJETIVO: Evaluar el efecto del programa de rehabilitación pulmonar (RP) del Instituto Neumológico del Oriente (INO), sobre los niveles de ansiedad y depresión en pacientes con ERC.

MATERIALES Y MÉTODOS: Estudio observacional analítico, cohorte retrospectiva en pacientes $>18$ años que finalizaron 48 sesiones del programa de RP del INO entre 2018 y 2019. Datos iniciales y finales de los cuestionarios de ansiedad (BAI) y depresión de Beck (BDI). Análisis bivariado con prueba exacta de Fisher, wilcoxon, U de Mann Whithney.

RESULTADOS: Inclusión de 85 pacientes, 58,8\% mujeres, con mediana de edad de 73 años. Hubo diferencias estadisticamente significativa en la distribución de los niveles de depresión al analizar por diagnostico respiratorio (Tabla1). Al comparar al inicio y al final del programa, hubo disminución significativa de la ansiedad y depresión ( $p<0.01$ ) (Tabla 2). Al analizar por sexo, la disminución de la ansiedad y depresión fue significativamente menor en mujeres $(\mathrm{P}<0,01)$ (Tabla 3).

Tabla 1. Diagnóstico respiratorio según la clasificación de ansiedady depresión en la línea basal

\begin{tabular}{|c|c|c|c|c|c|c|c|c|}
\hline \multirow[t]{2}{*}{ Diagnostico } & \multicolumn{3}{|c|}{$\begin{array}{c}\text { Depresión } \\
\text { N (\%) }\end{array}$} & \multicolumn{5}{|c|}{$\begin{array}{c}\text { Ansiedad } \\
\text { N (\%) }\end{array}$} \\
\hline & Minima & Leve & Moderada & & Mínima & Leve & Moderada & \\
\hline EPOC (n:49) & $36(73,5)$ & $9(18,4)$ & $4(8,16)$ & & $39(79,6)$ & $9(18,4)$ & $1(2,0)$ & \\
\hline Asma (n:15) & $7(46,7)$ & $8(53,3)$ & $0(0,0)$ & & $12(80,0)$ & $3(20,0)$ & $0(0,0)$ & \\
\hline Fibrosis $(n: 4)$ & $2(50,0)$ & $0(0,0)$ & $2(50,0)$ & & $3(75,0)$ & $1(25,0)$ & $0(0,0)$ & \\
\hline $\begin{array}{l}\text { Hipertensión } \\
\text { pulmonar (n:6) }\end{array}$ & $4(66,7)$ & $1(16,7)$ & $1(16,7)$ & 0,025 & $4(66,7)$ & $2(33,3)$ & $\mathrm{O}(0,0)$ & 0,345 \\
\hline Disnea ( $n: 6)$ & $1(33,3)$ & $1(33,3)$ & $1(33,3)$ & & $1(33,3)$ & $1(33,3)$ & $1(33,3)$ & \\
\hline Otros (n:8) & $7(87,5)$ & $1(12,5)$ & $0(0,0)$ & & $5(62,5)$ & $3(37,5)$ & $0(0,0)$ & \\
\hline
\end{tabular}

Tabla 2. Cambio en los niveles de ansiedad y depresión en la población de estudio posterior a las 4 fases de rehabilitación pulmonar.

\begin{tabular}{|c|c|c|c|c|c|}
\hline \multirow[t]{2}{*}{ Ansiedad inicial } & \multicolumn{3}{|c|}{$\begin{array}{c}\text { Ansiedad final } \\
N(\%)\end{array}$} & \multirow[b]{2}{*}{ Total } & \multirow[t]{2}{*}{$\begin{array}{c}\text { Valor } \\
p^{1}\end{array}$} \\
\hline & Mínima & Leve & Moderada & & \\
\hline Mínima & $55(85,9)$ & $6(9,4)$ & $3(4,7)$ & $64(100,0)$ & $<0,01$ \\
\hline Leve & $12(63,2)$ & $7(36,8)$ & $0(0,0)$ & $19(100,0)$ & \\
\hline Moderada/severa & $0(0,0)$ & $0(0,0)$ & $2(100,0)$ & $2(100,0)$ & \\
\hline Total & $67(78,8)$ & $13(15,3)$ & $5(5,9)$ & $85(100,0)$ & \\
\hline Depresión inicial & \multicolumn{3}{|c|}{$\begin{array}{l}\text { Depresión final } \\
\qquad N(\%)\end{array}$} & & \\
\hline Minima & $55(96,5)$ & $2(3,5)$ & $0(0,0)$ & $57(100,0)$ & $<0,01$ \\
\hline Leve & $11(55,0)$ & $5(25,0)$ & $4(20,0)$ & $20(100,0)$ & \\
\hline Moderada/severa & $2(25,0)$ & $2(25,0)$ & $4(50,0)$ & $8(100,0)$ & \\
\hline Total & $68(80,0)$ & $9(10,6)$ & $8(9,4)$ & $85(100,0)$ & \\
\hline
\end{tabular}

Tabla 3. Cambio en los puntajes de los inventarios de Beck de ansiedady depresión

\begin{tabular}{lcccccc}
\hline \multirow{2}{*}{ Variable } & \multicolumn{2}{c}{ Depresión } & Valor $p^{5}$ & \multicolumn{2}{c}{ Ansiedad } & Valor $p^{4}$ \\
& Femenino & Masculino & & Femenino & Masculino & \\
\hline Puntaje Inicial: & $7,94(0.70)$ & $3,0(0.21)$ & 0,01 & $5,06(0.22)$ & $2,9(0-17)$ & 0,01 \\
Puntaje Final: & $5,18(0-39)$ & $1,6(0.17)$ & $<0,01$ & $5,32(0.27)$ & $2,51(0.21)$ & 0,01 \\
Delta? $^{2}$ & $2,76(11,7)$ & $1,4(2,95)$ & 0,52 & $-0,26(6,67)$ & $0,4(4,35)$ & 0,58 \\
\hline Valor $^{3}$ & 0,02 & 0,01 & & 0,36 & 0,53 & \\
\hline
\end{tabular}

1: Media (Min-Max); 2: Media (DE); 3: Offerencia intra grupo, test de Wilcoxon; 4 testu de Mann-Withney

CONCLUSIONES: El programa de rehabilitación pulmonar disminuye los niveles de ansiedad y depresión siendo menor el impacto en las mujeres. 